\title{
Drug Law Enforcement Revisited: The "War" Against the War on Drugs
}

\section{Konstantinos Alexandris Polomarkakis'}

\begin{abstract}
From the closure of London's nightclub Fabric to Duterte's drug war, law enforcement has become the policy choice par excellence for drug control by stakeholders around the globe, creating a rift between theory and practice, the former vehemently dismissing most of its alleged benefits. This article provides a fresh look on the said regime, through examining its implications in the key areas of illicit drug markets, public health, and broader society. Instead of adopting a critical stance from the start, as much of the literature does, the issue is evaluated from the perspective of a focus on the logic and rationality of drug law enforcement approaches, to showcase from within how problematic the latter are. The article concludes by suggesting at least a reconceptualization of the concept, to give way to more sophisticated policies for finally tackling the issue of illegal drugs effectively.
\end{abstract}

\section{Keywords}

drug policy, war on drugs, law enforcement, drugs, illicit substances

\section{Introduction}

Law enforcement has been proclaimed as the most prevalent policy choice insofar as drug control is concerned. Few countries are more tolerant and put emphasis on a medical approach, through treatment provision (Bennett \& Holloway, 2005). Instead, it seems that the majority supports a harm-minimization model based on coercion, prohibition, and criminalization as panacea in limiting the supply and use of illegal drugs (Kerr, Small, \& Wood, 2005). This view comes in direct confrontation with a considerable part of the academic community that perceives law enforcement as inadequate - or failed - in achieving the said objectives (Wodak, 2001). Furthermore, those scholars strive for drug use to "be regarded as primarily a health and social issue, with funding raised for these measures to the level of drug law enforcement" (Wodak, 2001, p. 866). Thus, another perspective is forged, challenging the long-standing policy of enforcement. In addition, the latter's criticism also highlights its shortcomings in dealing with the issue of illegal drugs and their misuse; had it been successful, not many voices to the contrary

\footnotetext{
IUniversity of Bristol Law School, UK
}

\section{Corresponding Author:}

Konstantinos Alexandris Polomarkakis, University of Bristol Law School, Wills Memorial Building, Queen's Road, Bristol BS8 IRJ, UK.

Email: k.alexandris-polomarkakis@bristol.ac.uk 
would have been heard. Law enforcement's adverse effects seem to spread across multiple fields, outweighing its potentially beneficial outcomes.

The present article is an attempt to investigate this viewpoint, starting with a general overview of the concept of law enforcement, its underpinnings, and the rationale behind it. Next, the problématique surrounding it is to be presented, to continue with its potential benefits, which seem not to be easily identifiable in the long run. The biggest share of this article is to be occupied by the analysis of law enforcement's shortcomings at both theoretical and practical levels with the use of country-examples where necessary. Finally, the conclusion would support the thesis that law enforcement does indeed more harm than good.

\section{Law Enforcement as a Concept}

As the centerpiece of - virtually every-drug policy worldwide, law enforcement is used to alleviate the harmful effects drugs have on people and society in general. The relevant drug legislation has been shaped around the concepts of "life sentences, anti-laundering measures and forfeiture and confiscation of assets" (Dorn \& South, 1990, p. 173), which belong to the criminal justice system. Therefore, the aim of this strategy is to incapacitate and punish the offender, to act as a personal and general deterrent, as well as to rehabilitate (Herring, 2014). In turn, this consequentialist justification for criminalization is linked with drug use being considered as a wrong, causing harm not only mainly to others but also to drug users themselves (Shiner, 2006).

The moral logic behind enforcement is further underpinned by the international community, mainly through the UN conventions of 1961, 1971, and 1988, which promoted the criminalization of drug possession, use, and manufacture (Wood, Werb, Marshall, Montaner, \& Kerr, 2009). These were reaffirmed in UN sessions on drugs that followed and in the new 5-year deal United Nations is to fund in Iran, whereby capital punishment is still in use, provoking vivid opposition due to pressing and glaring human rights concerns (Dehghan, 2015). United Nations's policy choice acted as the paradigm for many countries' choices in the field of drug control. The United States and Mexico are prime examples of avid supporters of the drug law enforcement regime, having been among the first countries to raise the flags of the war on drugs, a war whose results are as ambivalent as the choice of starting it in the first place. Despite that, other countries, such as the United Kingdom, which had adopted different trajectories in the past, seemed to follow, displacing the medical approach in favor of law enforcement (Stimson, 1987). The war on drugs became mainstream, with the Duterte regime in Philippines being the latest example of this trend.

Ideologically rooted in the theory of harmfulness and drawing from a paternalistic assumption of wrongness in drug use (Ruggiero, 1999), law enforcement regard drugs as an evil that needs to be eradicated. For those considering law enforcement as the optimal solution to the problem, they should also bear in mind that it is possibly the most extreme one as well, as it involves harsh criminal sanctions. Treatment and prevention come second in terms of both importance and expenditure therein (Pearson, 2001). This is precisely where the oxymoron of law enforcement lies; while being morally justifiable, it is unclear if it is practically so too. To be the latter, its benefits shall outweigh its costs, based on the principle of proportionality. This, following a utilitarian tradition, implies that the measures adopted have to be legitimate, suitable, and necessary for achieving the goal that the state pursuits (Lacey, 1988; Shiner, 2006). In other words, efficiency is a key ingredient for a successful and justifiable legislative intervention (Lacey, 1988), together with parsimony, which calls for the minimum amount of intervention possible (Braithwaite \& Pettit, 1990).

The aims of drug law enforcement cannot be attained, if these principles are not met. In turn, this affects the former's moral position which might no longer be sustainable. Drug law enforcement risks becoming a house of cards, yet, at the same time, people would continue to be exposed to harm. As has already been noted, harm is the key word for justifying this regime. Its use as a 
justification is unproblematic if it refers to violent behavior toward others. On the contrary, the situation becomes trickier if it concerns the harm inflicted to oneself. How is it possible to assess harm, let alone justify countervailing measures, in these cases? Lacey (1988) argued that such harm reduction intervention is acceptable, only if it aims for preventing long-term negative effects to one's fundamental interests, namely, one's future welfare and well-being. If those fundamental interests are absent, then the chances of serious harm to surface are far and between, turning law enforcement into a coercion strategy to regulate a person's potentially risky or socially unacceptable lifestyle, often associated with the dominant views of the middle class (Miller, 2001). This cannot help but recall the new deviancy, social control and victimless crimes discourse of the 1960s and 1970s (Duster, 1970; Schur, 1965).

\section{The "Benefits" of Drug Law Enforcement}

For a model with such shaky foundations as this one to be upheld, its benefits should far outweigh its shortcomings. Or a cost-benefit analysis of drug law enforcement, another aspect of its intrinsic middle-class values (Miller, 2001), must have concluded prior to its adoption. While it is difficult to holistically evaluate all its alleged benefits, the economic theory of criminal law enforcement supports a positive outcome (Becker, 1968). This theory is based on the deterrence hypothesis, which

asserts that people respond significantly to the deterring incentives created by the criminal justice system. If so, increasing the resources that society devotes [to the latter] . . may be the best policy prescription for reducing the amount, and social costs, of crime. (Garoupa, 1997, p. 267)

This further bolstered the moral view for deterrence and its economics-based conception implying that benefits would occur in practice.

Advocates of the war on drugs strategy, such as George H. W. Bush, provided data that showed positive results in the United States, namely, large decreases in monthly drug use, deriving from the relevant harsh punitive policies (Meares, 1998). Of course, such data were contested by scholars, as other factors unrelated to drug policy per se, such as the recession in the early 1990s and demographic trends, that might have had an impact on the decrease were not taken into account (Degenhardt et al., 2008). Another benefit, not directed to the people but to the state, is that the latter regained its legitimation narrative. This was achieved through the reinforcement of control and the reconfiguration of penal welfarism (Garland, 2001), cultivated by the growing perception of drugs as a threat, which has provided the concept with significant ammunition (Elvins, 2003). In times of welfare state crisis, a new narrative was needed, which was provided by the notions of crime and fear that accompanies it, two powerful notions in justifying state intervention and letting a state authority to govern (Shiner, 2013). For those in power, law enforcements can be proven a valuable ally, adding some covert benefits into the game. These relate to the reinforcement of state power via crime and fear narratives of policy elites (Simon, 2008); the ancient saying of divide and conquer was transformed to terrify and govern. The fearsome rhetoric of the "war on drugs" has enabled further state intervention, to the point of coercion, in people's everyday lives, in way that resembles an Orwellian nightmare (McCulloch, 2007). Duterte's "war on drugs" is a good example of that; the fine line between myth and reality has become severely blurred (Levine, 2002).

\section{Drug Law Enforcement and Illegal Drug Markets}

Continuing our analysis, it is time to deal with the implications and costs of drug law enforcement. Among its goals, a twofold one exists, aiming for reduction in both demand and supply 
sides of illicit substances, through the application of criminal law (Lambropoulou, 2003). The setting is usually the illegal drug market scene, purportedly fragmented in different formations, from street dealers to drug brokers in exclusive settings to organized crime networks, which, while overlapping, do not allow for much transfer of information among the stakeholders involved at the various levels (Pearson, 2007). Enforcement strategies therein take the shape of measures directed toward "persons (arresting traffickers/couriers on the spot when intercepted); drugs (seizures); organisations (breaking up trafficking networks); and, income generated by criminal activity (financial investigations and confiscation of assets)" (Ellis, Denney, Nee, \& Barberet, 2002, p. 109).

Insofar as the people involved are concerned, the failure of law enforcement policies lies in the fact that while the quantities supplied are reduced as a result of an increased probability of detection, the actual number of traffickers in a market is multiplied. Thus, new players are allowed in an already established place, negating the effects of any decrease in quantity. A study focused on explaining why the war on drugs by the United States in Colombia has not been proven effective confirms these assumptions, further explaining that the increased number of traffickers hinders police efforts for enforcement (Poret \& Tejedo, 2006). Of course this does not mean that law enforcement aggravates the situation. As illegal drug markets are modeled after noncartelized oligopolies, the entry of new traffickers distorts this ideal-type without, subsequently, increasing the market's output (Kopp, 2004). In the end, law enforcement does not seem to have almost any impact in its people-related strategies, the illicit drugs market being able to adapt to the changes incurred by them.

In regard to the drug-related side of law enforcement, the most commonly used method is drug seizure, focusing on reducing their supply. Studies on the efficiency of such strategies mainly use heroin as their variable, and their explanatory framework is comprised of the effects of seizures on price, purity, or availability (Mazerolle, Soole, \& Rombouts, 2007). These do not seem to be affected by law enforcement in the said form neither in Australia (Weatherburn \& Lind, 1997, 2001) nor in Canada (Wood et al., 2003). Earlier data in the United States, however, show some progress in heroin and cannabis - albeit not accompanied with any significant drop in use in either-but not in cocaine (Moore, 1990). More recent U.K. data demonstrate that there is a tendency in constantly falling market prices for most substances, showcasing the resilience of drug markets when confronted with seizures (McSweeney, Tumbull, \& Hough, 2008). The fallen prices might be a result of globalization, which "offsets the effects of supply containment policies" (Storti \& De Grauwe, 2009, p. 488).

In any case, drug markets evolve in response to enforcement efforts, efforts that increase the professionalization of the trade therein (Dorn \& South, 1990). If production is stopped in Country A, then it might automatically soar in Country B (Paoli, Greenfield, \& Reuter, 2009). Another relevant point, in particular regarding the more sophisticated aspects of criminal organizations and their activities, is that intensifying enforcement activity increases disorder in the targeted area, resulting in higher rates of homicides and gun violence to combat police intervention (Werb et al., 2011). Mexico, tarnished by drug-related violence, can easily support this claim. The government's war-like stance on tackling the country's long-standing drug problem is considered as a key driver for crime and violence in the relevant markets, affecting people outside of them as well (Widner, Reyes-Loya, \& Enomoto, 2011). Consequently, enforcement in illicit drugs fora has been proven negligible at best, with harsher forms of it being responsible for having severely adverse consequences.

\section{Drug Law Enforcement and Public Health}

These adverse outcomes can also occur in areas pertaining to the public health sphere. Studies have shown that injecting drug users adapt their behavior, by rushing during the injection phase, 
in fear of a police crackdown (Kerr et al., 2005). Such behavior usually involves a hurried preparatory stage, increasing risks for infections and vascular damage (Maher \& Dixon, 1999, 2001; Murphy et al., 2001). At the same time, it disconnects "street-based injectors from health and other service providers" (Aitken, Moore, Higgs, Kelsall, \& Kerger, 2002, p. 194). Moreover, police presence deters users from using syringe exchange programs. As a study of the metropolitan San Francisco area has shown, law enforcement had a negative impact in terms of arresting both volunteers in such programs and potential clients, leading the latter to resort to riskier practices (Bluthenthal, Kral, Lorvick, \& Watters, 1997). Therefore, any serious harm reduction strategy can, potentially, be jeopardized by law enforcement. The users, in a panicked mood, either do not check the quality of the drugs they are taking or fail to comply with the appropriate procedures, increasing chances for overdose and damaging their health (Cooper, Moore, Gruskin, \& Krieger, 2005).

A cross-county analysis of U.S. data confirmed the link between higher rates of law enforcement and HIV prevalence among injecting drug users, further showing that, in terms of deterrence in injecting, these strategies have no impact at all (Friedman et al., 2006). To tackle these issues, some alternatives have been promoted, mainly by modifying policing practices. These involve aborting the crackdown model, trying, instead, to forge close co-operation between the police, governmental and nongovernmental organizations, and community members (Cooper, Moore, Gruskin, \& Krieger, 2004). That way, harm reduction initiatives would be able to function effectively, as, for example, in the case of North America's first state sanctioned supervised injection facility in Vancouver (Small, Palepu, \& Tyndall, 2006).

\section{Drug Law Enforcement and Broader Society}

Nondrug using members of society do not remain unscathed from the impact of law enforcement either. Community safety is at stake because injecting drug users that get caught would probably resort to crime once more, to try injecting again, and, also, because failed dealers would attempt other types of crime for making some profit (Maher \& Dixon, 1999). At another important level, "police policies and practices associated with the war on drugs have been the most influential in perpetuating racially discriminatory police discretionary behaviour" (Bass, 2001, p. 164). This view is particularly prevalent in the United States, whereby the criminal justice systems seem to use drug law enforcement as a tactic to perpetuate racial discrimination toward African Americans, leading authors to call this phenomenon "the New Jim Crow" (Alexander, 2012). Studies of drug activity in Seattle confirm the existence of racial disparity in terms of people arrested, despite the dominance of White people in all drug markets except that of crack cocaine (Beckett, Nyrop, \& Pfingst, 2006).

In the United Kingdom, the majority of people not only targeted by the "stop and search" policy but also being subsequently arrested are predominantly of Black origin as well (Eastwood, Shiner, \& Bear, 2013). This can be explained by the limited resources these people might have compared with a wealthier, White population, highlighting the shortcomings of applying a single police strategy (Cooper et al., 2005). For example, White men of a homeless community in San Francisco were found to carry syringes more often compared with Black ones, due to the latter's fear of arrest (Bourgois, Lettiere, \& Quesada, 1997). Nonetheless, African Americans are not the only group victimized by law enforcement; in the Australian suburb of Cabramatta, men and especially those of young age and of Asian origin are more prone to police crackdowns and, hence, less likely to follow the procedures of safely injecting themselves (Maher \& Dixon, 1999).

\section{Path-Dependence and Lack of High Quality Research}

The war on drugs tactic has also been economically costly, with the money attributed to it probably having a better use in other-more effective - harm reduction strategies (Alexander, 1990). 
Of course once law enforcement was in place, then it became difficult to fundamentally deviate from it due to the complex nature of policy-making that, sometimes, deters bold initiatives (Stevens, 2011). If the stakes are high for bureaucracies, then misinformation could be created to exaggerate the chosen method's potential benefits (Benson, Rasmussen, \& Sollars, 1995). Supporting claims based on the number of arrests and seizures are not enough for assessing drug law enforcement (Bright \& Ritter, 2010). Even the more sophisticated assumption that targeting the supply-side of drug markets would incur a price increase can be problematic. In fact, it is a rather myopic one as other components that might interfere and affect drug consumption patterns, including their prices, are not taken into account (Poret, 2003).

This underlines the lacunae in framing law enforcement's objectives, which should move away from supply reduction and suppression. Instead, they should conform to harm reductionrelated goals, with methods of measurement tailored to achieving those (Trace, 2012). On the contrary, even the numerous studies on the costs of law enforcement have been judged as flawed in terms of the methodological design employed therein (Mason \& Bucke, 2002). As Mazerolle et al. (2007) observed, "the general quality of research in drug law enforcement is poor, the range of interventions that have been evaluated is limited, and more high-quality research is needed across a greater variety of interventions" (p. 138). Notwithstanding that the scholarship in that regard is still valuable as its main point, the ineffectiveness of the drug law enforcement regime is systematically proven, albeit with discrepancies in the methods followed. Thus, a more streamlined approach would be beneficial for making a stronger case for this argument.

\section{Conclusion}

From what has been set down supra, it appears that the associated costs of drug law enforcement far outweigh its benefits. The latter are difficult to identify and measure in terms of their effectiveness, bearing in mind that supply reduction - and even market price- has more often than not little to do with drug control. On the contrary, drug law enforcement exacerbates and increases harms to users, worsens public health levels, and reproduces social exclusion and division, through patterns of race disadvantage. Its negative implications spread across various levels and fields, be it in the organization of drug markets per se, the people involved therein, or society in general. Furthermore, all these highlight the quick adaptability of the drug scene to any of its forms and, at the same time, law enforcement's slow response to the challenges posed by the current situation. Things are to get even more challenging with the emergence of new technologies, either in their use to facilitate e-trade, as well as to evade and even counteract control through cyber-attacks (Ghodse, 2008), or in the production of new legal-highs. As a crime control strategy, law enforcement has, consequently, failed to achieve its goals.

In the realm of policy though, the situation is different, with this model being a successful political project in reinforcing the somewhat lost state-exercised notion of control over its people. The international community still supports this tactic, showcasing a paradoxical persistence, fueling the analysis of how difficult long-established policies are to change. The persistence of drug law enforcement was further driven by the tendency for convergence through a globalization of processes including but not limited to the field of criminal justice, fueled by a neo-liberal discourse (Muncie, 2005). Despite the strong path dependence, there is a plethora of literature studying the implications of law enforcement to the aforementioned areas, and strongly suggesting a need for a change in the form of either its reconceptualization or its scrapping altogether in favor of another policy. These voices, while inconsistent in terms of the methods employed in their studies, shall be heard if a change in the current situation is to occur. Fighting a war with inappropriate strategies and/or weapons hardly ever guarantees winning it. 


\section{Declaration of Conflicting Interests}

The author(s) declared no potential conflicts of interest with respect to the research, authorship, and/or publication of this article.

\section{Funding}

The author(s) received no financial support for the research, authorship, and/or publication of this article.

\section{References}

Aitken, C., Moore, D., Higgs, P., Kelsall, J., \& Kerger, M. (2002). The impact of a police crackdown on a street drug scene: Evidence from the street. International Journal of Drug Policy, 13, 193-202.

Alexander, B. (1990). Peaceful measures: Canada's way out of the war on drugs. Toronto, Ontario, Canada: University of Toronto Press.

Alexander, M. (2012). The new Jim Crow. New York, NY: The New Press.

Bass, S. (2001). Policing space, policing race: Social control imperatives and police discretionary decisions. Social Justice, 28(1), 156-176.

Becker, G. S. (1968). Crime and punishment: An economic approach. Journal of Political Economy, 76, 169-217.

Beckett, K., Nyrop, K., \& Pfingst, L. (2006). Race, drugs, and policing: Understanding disparities in drug delivery arrests. Criminology, 44, 105-137.

Bennett, T., \& Holloway, K. (2005). Understanding drugs, alcohol and crime. Maidenhead, UK: Open University Press.

Benson, B., Rasmussen, D., \& Sollars, D. (1995). Police bureaucracies, their incentives, and the war on drugs. Public Choice, 83, 21-45.

Bluthenthal, R., Kral, A., Lorvick, J., \& Watters, J. (1997). Impact of law enforcement on syringe exchange programs: A look at Oakland and San Francisco. Medical Anthropology: Cross-Cultural Studies in Health and Illness, 18, 61-83.

Bourgois, P., Lettiere, M., \& Quesada, J. (1997). Social misery and the sactions of substance abuse: Confronting HIV risk among homeless heroin addicts in San Francisco. Social Problems, 44, 155-173.

Braithwaite, J., \& Pettit, L. (1990). Not just deserts: A republican theory of criminal justice. Oxford, UK: Clarendon Press.

Bright, D., \& Ritter, A. (2010). Retail price as an outcome measure for the effectiveness of drug law enforcement. International Journal of Drug Policy, 21, 359-363.

Cooper, H., Moore, L., Gruskin, S., \& Krieger, N. (2004). Characterizing perceived police-related abuse: Contributions to public health research, interventions, and advocacy concerning violence. American Journal of Public Health, 94, 1109-1118.

Cooper, H., Moore, L., Gruskin, S., \& Krieger, N. (2005). The impact of a police drug crackdown on drug injectors' ability to practice harm reduction: A qualitative study. Social Science \& Medicine, 61, 673-684.

Degenhardt, L., Chiu W.-T., Sampson, N., Kessler, R. C., Anthony, J. C., Angemeyer, M., ...Elisabeth Wells, J. (2008). Toward a global view of alcohol, tobacco, cannabis, and cocaine use: Findings from the WHO world mental health surveys. PLoS Medicine, 5, 1053-1067.

Dehghan, S. K. (2015, March 19). UN to fund Iran anti-drugs programme despite executions of offenders. The Guardian. Retrieved from https://www.theguardian.com/world/2015/mar/19/un-fund-iran-antidrugs-programme-executions-unodc-death-penalty

Dorn, N., \& South, N. (1990). Drug markets and law enforcement. British Journal of Criminology, 30, 171-188.

Duster, T. (1970). The legislation of morality: Law, drugs and moral judgment. New York, NY: The Free Press.

Eastwood, N., Shiner, M., \& Bear, D. (2013). The numbers in Black and White: Ethnic disparities in the policing and prosecution of drug offences in England and Wales. London, England: Release.

Ellis, T., Denney, D., Nee, C., \& Barberet, R. (2002). Cocaine markets and drug enforcement in Spain and The Netherlands. The Police Journal, 75, 101-110. 
Elvins, M. (2003). Anti-drug policies of the European union: Transnational decision-making and the politics of expertise. Basingstoke, UK: Palgrave MacMillan.

Friedman, S. R., Cooper, H. L. F., Tempalski, B., Keem, M., Friedman R., Flom, P. L., \& Des Jarlais, D. C. (2006). Relationships of deterrence and law enforcement to drug-related harms among drug injectors in US metropolitan areas. AIDS, 20, 93-99.

Garland, D. (2001). The culture of control. Oxford, UK: Oxford University Press.

Garoupa, N. (1997). The theory of optimal law enforcement. Journal of Economic Surveys, 11, 267-295.

Ghodse, H. (Ed.). (2008). International drug control in the 21st century. Aldershot, UK: Ashgate.

Herring, J. (2014). Criminal law: Text, cases and materials. Oxford, UK: Oxford University Press.

Kerr, T., Small, W., \& Wood, E. (2005). The public health and social impacts of drug market enforcement: A review of the evidence. International Journal of Drug Policy, 16, 210-220.

Kopp, P. (2004). Political economy of illegal drugs. London, England: Routledge.

Lacey, N. (1988). State punishment: Political principles and community values. London, England: Routledge.

Lambropoulou, E. (2003). Drug policy in Greece: A balance between enforcement and persuasion. European Journal of Crime, Criminal Law and Criminal Justice, 1, 18-39.

Levine, H. (2002). The secret of worldwide drug prohibition: The varieties and uses of drug prohibition. The Independent Review, 7, 165-180.

Maher, L., \& Dixon, D. (1999). Policing and public health: Law enforcement and harm minimization in a street-level drug market. British Journal of Criminology, 39, 488-512.

Maher, L., \& Dixon, D. (2001). The cost of crackdowns: Policing Cabramatta's heroin market. Current Issues in Criminal Justice, 13(1), 5-22.

Mason, M., \& Bucke, T. (2002). Evaluating actions against local drug markets: A systematic review of research. The Police Journal, 75, 15-30.

Mazerolle, L., Soole, D., \& Rombouts, S. (2007). Drug law enforcement: A review of the evaluation literature. Police Quarterly, 10, 115-153.

McCulloch, J. (2007). Transnational crime as productive fiction. Social Justice, 34(2), 19-32.

McSweeney, T., Tumbull, P. J., \& Hough, M. (2008). Tackling drug markets and distribution networks in the UK: A review of the recent literature. London, England: UK Drug Policy Commission.

Meares, T. (1998). Social organisation and drug law enforcement. American Criminal Law Review, 35, 191-227.

Miller, P. (2001). A critical review of the harm minimization ideology in Australia. Critical Public Health, $11,167-178$.

Moore, M. (1990). Supply reduction and drug law enforcement. Crime and Justice, 13, 109-157.

Muncie, J. (2005). The globalization of crime control-The case of youth and juvenile justice: Neoliberalism, policy convergence and international conventions. Theoretical Criminology, 9, 35-64.

Murphy, E. L., DeVita, D., Liu, H., Vittinghoff, E., Leung, P., Ciccarone, D. H., Edlin, B. R. (2001). Risk factors for skin and soft-tissue abscesses among injection drug users: A case-control study. Clinical Infectious Diseases, 33(1), 35-40.

Paoli, L., Greenfield, V., \& Reuter, P. (2009). The world heroin market: Can supply be cut? New York, NY: Oxford University Press.

Pearson, G. (2001). Book review, illegal drug markets: From research to prevention policy. International Journal of Drug Policy, 12, 371-374.

Pearson, G. (2007). Drug markets and dealing: From street dealer to Mr Big. In M. Simpson, T. Shildrick, \& R. MacDonald (Eds.), Drugs in Britain: Supply, consumption and control (pp. 76-92). Basingstoke, UK: Palgrave MacMillan.

Poret, S. (2003). Paradoxical effects of law enforcement policies: The case of the illicit drug market. International Review of Law and Economics, 22, 465-493.

Poret, S., \& Tejedo, C. (2006). Law enforcement and concentration in illicit drug markets. European Journal of Political Economy, 22, 99-114.

Ruggiero, V. (1999). The legalisation of illicit substances. In N. South (Ed.), Drugs: Cultures, controls and everyday life. London, England: SAGE.

Schur, E. (1965). Crimes without victims: Deviant behaviour and public policy, abortion, homosexuality, drug addiction. Englewood Cliffs, NJ: Prentice Hall. 
Shiner, M. (2006). Drugs, law and the regulation of harm. In R. Hughes, R. Lart, \& P. Higate (Eds.), Drugs: Policy and politics (pp. 59-74). Maidenhead, UK: Open University Press.

Shiner, M. (2013). British drug policy and the modern state: Reconsidering the criminalisation thesis. Journal of Social Policy, 42, 623-643.

Simon, J. (2008). Governing through crime: How the war on crime transformed American democracy and created a culture of fear. Oxford: Oxford University Press.

Small, D., Palepu, A., \& Tyndall, M. (2006). The establishment of North America's first state sanctioned supervised injection facility: A case study in culture change. International Journal of Drug Policy, 17, 73-82.

Stevens, A. (2011). Telling policy stories: An ethnographic study of the use of evidence in policy-making in the UK. Journal of Social Policy, 40, 237-255.

Stimson, G. V. (1987). British drug policies in the 1980's: A preliminary analysis and suggestions for research. British Journal of Addiction, 82, 477-488.

Storti, C. C., \& De Grauwe, P. (2009). The cocaine and heroin markets in the era of globalisation and drug reduction policies. International Journal of Drug Policy, 20, 488-496.

Trace, M. (2012). Measuring drug law enforcement-From process to outcomes. International Journal of Drug Policy, 23, 17-18.

Weatherburn, D., \& Lind, B. (1997). The impact of law enforcement activity on a heroin market. Addiction, 92, 557-569.

Weatherburn, D., \& Lind, B. (2001). Street-level drug law enforcement and entry into methadone maintenance treatment. Addiction, 96, 577-587.

Werb, D., Rowell, G., Guyatt, G., Kerr, T., Montaner, J., \& Wood, E. (2011). Effect of drug law enforcement on drug market violence: A systematic review. International Journal of Drug Policy, 22, 87-94.

Widner, B., Reyes-Loya, M., \& Enomoto, C. (2011). Crimes and violence in Mexico: Evidence from panel data. The Social Science Journal, 48, 604-611.

Wodak, A. (2001). Drug laws: War on drugs does more harm than good. British Medical Journal, 323(7317), Article 866.

Wood, E., Tyndall, M. W., Spittal, P. M., Li, K., Anis, A. H., Hogg, R. S., ... Schechter, M. T. (2003). Impact of supply-side policies for control of illicit drugs in the face of the AIDS and overdose epidemics: Investigation of a massive heroin seizure. Canadian Medical Association Journal, 168, 165-169.

Wood, E., Werb, D., Marshall, B., Montaner, J., \& Kerr, T. (2009). The war on drugs: A devastating publicpolicy disaster. The Lancet, 373, 989-990.

\section{Author Biography}

Konstantinos Alexandris Polomarkakis is a teaching assistant and doctoral researcher at the University of Bristol Law School. His research interests lie in the field of socio-legal studies, focusing on the interplay between law and social policy, and more specifically on how judicial decision-making and law enforcement might affect welfare. 